Published in final edited form as:

J Am Chem Soc. 2018 May 30; 140(21): 6522-6526. doi:10.1021/jacs.8b02650.

\title{
Decarboxylative Trifluoromethylation of Aliphatic Carboxylic Acids
}

\author{
Jacob A. Kautzky $\ddagger$, Tao Wang ${ }^{\ddagger}$, Ryan W. Evans, and David W. C. MacMillan ${ }^{*}$ \\ Merck Center for Catalysis at Princeton University, Princeton, New Jersey 08544, United States
}

\begin{abstract}
Herein we disclose an efficient method for the conversion of carboxylic acids to trifluoromethyl groups via the combination of photoredox and copper catalysis. This transformation tolerates a wide range of functionality including heterocycles, olefins, alcohols, and strained ring systems. To demonstrate the broad potential of this new methodology for late-stage functionalization, we successfully converted a diverse array of carboxylic acid-bearing natural products and medicinal agents to the corresponding trifluoromethyl analogues.
\end{abstract}

In drug discovery, a commonly used strategy to protect against in vivo metabolism involves the incorporation of a trifluoromethyl group $\left(\mathrm{CF}_{3}\right)$ into medicinal candidates. Moreover, a variety of studies have shown that $\mathrm{CF}_{3}$ groups can increase the efficacy of a drug candidate by modulating protein-ligand interactions and improving membrane permeance, among other benefits. ${ }^{1}$ While significant advancements have been made in the development of general, catalytic protocols that access aryl $-\mathrm{CF}_{3}$ adducts, methods for the formation of aliphatic $\mathrm{C}_{\mathrm{sp} 3}-\mathrm{CF}_{3}$ bonds remain limited. ${ }^{2}$ Conventional approaches toward $\mathrm{C}_{\mathrm{sp} 3}-\mathrm{CF}_{3}$ installation include (i) difunctionalization of olefins via $\mathrm{CF}_{3}$ radical addition, ${ }^{3}$ (ii) nucleophilic substitution of alkyl halides or triflates with stoichiometric $\left[\mathrm{CuCF}_{3}\right]$ species, ${ }^{4}$ and (iii) oxidative coupling of alkyl boronic acids with $\left[\mathrm{CuCF}_{3}\right]$ reagents. ${ }^{5}$ These elegant methods nonetheless require the pre-activation of the coupling partner, a step that can often limit their potential utility in late-stage functionalization and other diversification steps. As such, the discovery of a catalytic trifluoromethylation mechanism that allows the conversion of native, abundant functional groups into $\mathrm{C}_{\mathrm{sp} 3}-\mathrm{CF}_{3}$ motifs should be of considerable value to medicinal chemists and the synthetic community as a whole.

The merger of transition metal and photoredox catalysis, termed metallaphotoredox catalysis, has enabled the discovery of a range of synthetically valuable and hitherto elusive transformations. ${ }^{6}$ In particular, carboxylic acids, a naturally abundant class of compounds,

\footnotetext{
*Corresponding Author: dmacmill@princeton.edu.

¥Author Contributions

J.A.K. and T.W. contributed equally.

The authors declare no competing financial interest.

ASSOCIATED CONTENT

Supporting Information

The Supporting Information is available free of charge on the ACS Publications website at DOI: 10.1021/jacs.8b02650.

General experimental protocols, procedure for optimization studies, general procedure for decarboxylative trifluoromethylation,

mechanistic studies, characterization data for all key compounds, and spectral data (PDF)
} 
can efficiently undergo decarboxylative cross-coupling via this dual catalysis platform to install a myriad of valuable functionalities including $\mathrm{C}_{\mathrm{sp} 3}$-aryl, —alkyl, — vinyl, and acyl groups. ${ }^{7}$ Indeed, the capacity of carboxylic acids to act as an adaptive functionality renders them ideal starting materials for both early- and late-stage bond formation.

Moreover, these methodologies generally employ mild conditions (i.e., visible light, room temperature) and exhibit broad functional group tolerance, features that allow for their use with a diverse array of complex, biologically relevant molecules. ${ }^{8}$ Recently, we questioned if a metallaphotoredox platform might enable a catalytic decarboxylative trifluoromethylation. As a key design element, we envisioned the use of copper as the key cross-coupling catalyst, effectively taking advantage of $\mathrm{Cu}^{\mathrm{III}}$ 's propensity to undergo facile reductive elimination from its high valency oxidation state. ${ }^{9}$ At the same time, we hoped that $\mathrm{C}_{\mathrm{sp} 3}$ - carboxylic acid bonds could be activated via photoredox to generate alkyl radicals that would rapidly engage in a copper catalytic cycle. Indeed, it is well-established that aliphatic open-shell intermediates will undergo capture by copper species at rates that approach rates of diffusion. ${ }^{10}$ This concept was recently employed by our laboratory in a $\mathrm{C}-\mathrm{N}$ heteroaryl bond-forming reaction wherein aliphatic carboxylic acids underwent decarboxylative coupling with many classes of $\mathrm{N}$-nucleophiles. ${ }^{11}$ Herein, we report the successful translation of this new strategy to $\mathrm{C}-\mathrm{C}$ bond formation and describe the first copper-catalyzed decarboxylative trifluoromethylation of aliphatic carboxylic acids.

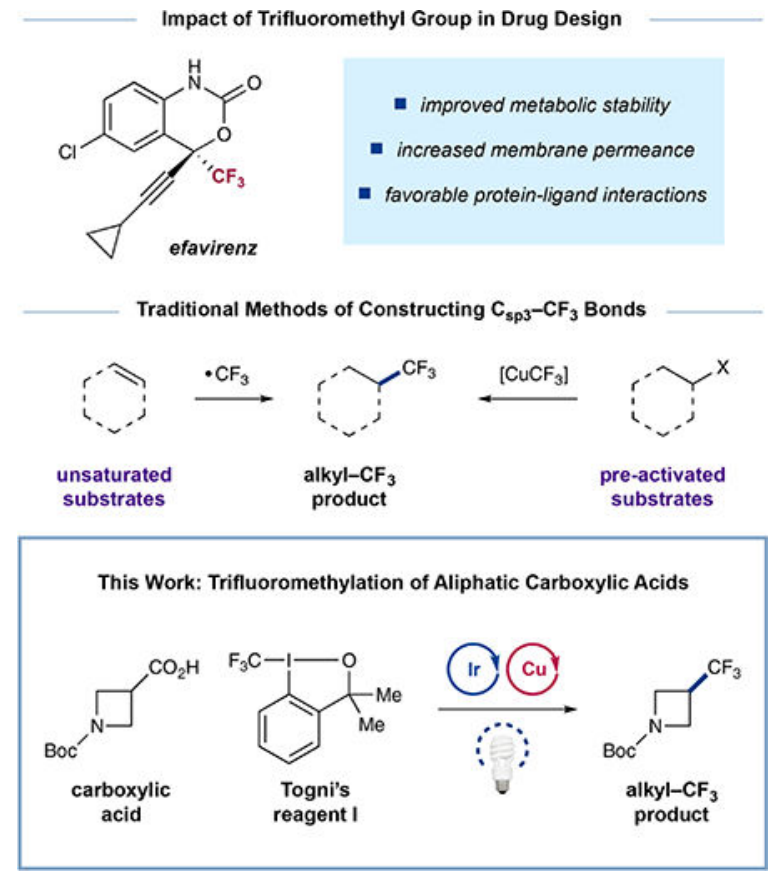

Details of the proposed dual copper-photoredox cycle are outlined in Scheme 1. We envisioned that photoexcitation of the Ir ${ }^{\mathrm{III}}$ photocatalyst $\operatorname{Ir}\left[\mathrm{dF}\left(\mathrm{CF}_{3}\right) \text { ppy }\right]_{2}\left(4,4^{\prime}-\mathrm{dCF}_{3}\right.$ bpy $) \mathrm{PF}_{6}$ (1) with visible light would generate the highly oxidizing excited-state * Ir ${ }^{\mathrm{III}} 2\left(E_{1 / 2}^{\mathrm{red}}\left[{ }^{*} \mathrm{Ir}^{\mathrm{III}} / \mathrm{Ir}^{\mathrm{II}}\right]=1.65 \mathrm{~V}\right.$ vs SCE in MeCN$) .{ }^{12}$ At the same time, the carboxylate anion derived from carboxylic acid 3 and base would ligate the $\mathrm{Cu}^{\mathrm{II}}$ catalyst. Single-electron transfer (SET) from copper carboxylate $\mathbf{4}$ to highly oxidizing excited-state $* \mathrm{Ir}^{\mathrm{III}} \mathbf{2}$ would 
then deliver $\mathrm{Cu}^{\mathrm{III}}$ carboxylate $\mathbf{5}$, or in the dissociated form, a carboxyl radical and $\mathrm{Cu}^{\mathrm{II}}$ complex (6), along with reduced $\mathrm{Ir}^{\mathrm{II}}$ photocatalyst 7 . The resulting carboxyl radical would extrude $\mathrm{CO}_{2}$ to generate an alkyl radical and $\mathrm{Cu}^{\mathrm{II}}(\mathbf{8})$, which would rapidly recombine to form $\mathrm{Cu}^{\mathrm{III}}$ species 9 . At this point, we hypothesize that a single-electron transfer would then occur between 9 and the reduced $\mathrm{Ir}^{\mathrm{II}}$ state of photocatalyst $7\left(E_{1 / 2}^{\mathrm{red}}\left[\mathrm{Ir}^{\mathrm{III}} / \mathrm{Ir}^{\mathrm{II}}\right]=-0.79 \mathrm{~V}\right.$ vs

$\mathrm{SCE}$ in $\mathrm{MeCN}$ ) to close the photoredox catalytic cycle and produce an alkylcopper(II) species (10). At this stage, we hoped that 10 would engage Togni's reagent I (11) to deliver alkyl $-\mathrm{CF}_{3}$ product 12 , presumably via reductive elimination from a transiently formed $\mathrm{Cu}^{\mathrm{III}}$ intermediate. ${ }^{13}$ This is in accord with previous stoichiometric studies in which an arylcopper(II) intermediate was trifluoromethylated. ${ }^{14}$ The resulting complex 13 would then undergo ligand exchange with substrate acid $\mathbf{3}$ to complete this dual-catalytic cycle.

Our investigation into this new decarboxylative trifluoromethylation began with exposure of 1-benzoylpiperidine-4-carboxylic acid (3) to various electrophilic trifluoromethyl sources ${ }^{13,15}$ in the presence of photocatalyst $\mathbf{1}, \mathrm{CuCl}_{2}, 3,4,7,8$-tetramethyl-1,10phenanthroline, and Barton's base (2-tert-butyl-1,1,3,3-tetramethylguanidine, BTMG) in ethyl acetate. To our delight, product formation was observed in 39\% yield when Togni's reagent I $\left(\mathbf{1 1}, \mathrm{E}_{\mathrm{p}}\left[\mathbf{1 1}^{\left.\mathbf{1 1 1} \mathbf{0}^{-}\right]}\right]=-1.51 \mathrm{~V} \text { vs SCE in } \mathrm{MeCN}\right)^{16}$ was used (Table 1, entry 3). More oxidizing $\mathrm{CF}_{3}$ sources such as Umemoto reagent $\left(\mathbf{1 4}, \mathrm{E}_{\mathrm{p}}\left[\mathbf{1 4}^{+} / \mathbf{1 4}^{\circ}\right]=-0.32 \mathrm{~V}\right.$ vs $\mathrm{SCE}$ in $\mathrm{MeCN}$, entry 1$)^{16}$ and Togni's reagent II $\left(\mathbf{1 5}, \mathrm{E}_{\mathrm{p}}\left[\mathbf{1 5}^{\mathbf{1 5}} \mathbf{5}^{-}\right]=-0.79 \mathrm{~V}\right.$ vs SCE in MeCN, entry 2) ${ }^{16}$ were not as efficient, presumably due to their unproductive reduction by the reduced photocatalyst $\left(\mathbf{7}, E_{1 / 2}^{\mathrm{red}}\left[\mathrm{Ir}^{\mathrm{III}} / \mathrm{Ir}^{\mathrm{II}}\right]=-0.79 \mathrm{~V}\right.$ vs $\mathrm{SCE}$ in $\left.\mathrm{MeCN}\right)$. Further evaluation revealed that the use of $\mathrm{CuCN}$ as the copper source, bathophenanthroline as the ligand, and addition of 30 equiv of water further improved the reaction efficiency (entry 5, 78\% isolated yield). It is worth noting that both $\mathrm{Cu}^{\mathrm{I}}$ and $\mathrm{Cu}^{\mathrm{II}}$ salts are capable precatalysts for this transformation. When $\mathrm{Cu}^{\mathrm{I}}$ sources such as $\mathrm{CuCN}$ are used, a significant change in color can be observed upon addition of Togni's reagent I, potentially due to a change in oxidation state of the copper species. This hypothesis is supported by in situ ${ }^{19} \mathrm{~F}$ NMR analysis, in which an equivalent of Togni's reagent is consumed upon mixing with a ligated $\mathrm{Cu}^{\mathrm{I}}$ species (see Supporting Information (SI) for details). It should be noted that sub-stoichiometric base ( 0.5 equiv, cf. Table 1, entry 6) is critical to the success of the reaction. Carboxylates are prone to form chelates with copper and deactivate the $\mathrm{Cu}$ catalyst. ${ }^{17}$ The tertiary alcohol byproduct originating from Togni's reagent I after transfer of the $\mathrm{CF}_{3}$ moiety ultimately serves as stoichiometric base (cf. 13 to 4). Control experiments revealed that photocatalyst, copper catalyst, and light were all essential for the success of this new decarboxylative trifluoromethylation protocol (Table 1, entries 7-9). With respect to the proposed mechanism, it is important to note that $\left[\mathrm{CuCF}_{3}\right]$ was not detected by ${ }^{19} \mathrm{~F}$ NMR analysis $(<1$ mol\%). This mechanism contrasts with the recent studies of the Li group, whereby stoichiometric $\mathrm{Cu}\left(\mathrm{CF}_{3}\right)_{\mathrm{X}}$ was used to capture alkyl radicals. ${ }^{18}$ Moreover, mechanistic experiments reveal a copper-mediated decarboxylation is likely operative (see SI for details).

With optimized conditions in hand, we sought to evaluate the scope of the $\mathrm{C}_{\mathrm{sp} 3}-\mathrm{CF}_{3}$ bondforming reaction. As shown in Table 2, a myriad of primary carboxylic acids are successful substrates, providing the corresponding $\mathrm{CF}_{3}$ analogue in good to excellent yield. 
Phenylacetic acids are generally competent, with a diverse range of electron-withdrawing (16-19, 70-80\% yield), electron-donating (20, 74\% yield), and electron-neutral substituents (21 and 22, 60 and 70\% yield, respectively) tolerated on the aryl ring. Notably, the efficacy of the reaction was not hindered by ortho substitution (20,74\% yield), and useful levels of efficiency were observed for an ortho,ortho-disubstituted heterocycle (26, 30\% yield). Notably, boronic esters and aryl bromides were also tolerated using this mild coppercatalyzed protocol, with no chemoselectivity issues (17 and $\mathbf{2 1}, 80$ and 60\% yield, respectively). The reaction is also amenable to a range of non-benzylic primary acids (2733, 31-82\% yield). Moreover, substrates incorporating $\beta, \beta$-branching afforded the desired product in good yields ( $\mathbf{3 1}$ and $\mathbf{3 2}, 63$ and $71 \%$ yield, respectively) revealing that steric constraints can be overcome. Gratifyingly, an array of heterocycles, many of which include basic nitrogens, can be utilized in this transformation (23-26 and 28-30, 30-70\% yield).

We next turned our attention to secondary and tertiary carboxylic acids (34-51, 45-93\% yield). We were pleased to find that cyclic carboxylic acids, including strained 3- and 4membered rings, participate in this trifluoromethylation in moderate to excellent yield (39$\mathbf{4 5}, 45-83 \%$ yield). Several bicyclic and spirocyclic compounds $(\mathbf{3 8}, \mathbf{3 9}, \mathbf{4 2}$, and $\mathbf{4 5}, 45-83 \%$ yield) formed the desired bond with good efficiency. This is a significant finding given that many of these bicyclic systems serve as aryl ring bioisosteres in drug design. ${ }^{19}$ Moreover, acyclic systems also produced the desired $\mathrm{CF}_{3}$ product in good efficiency $(\mathbf{4 6}-\mathbf{4 8}, 50-56 \%$ yield). Notably, the compatibility of this reaction with medicinally relevant structures was demonstrated with a $\beta$-lactam $(\mathbf{4 6}, 53 \%$ yield). Last, a number of tertiary carboxylic acids were also successfully converted to $\mathrm{C}_{\mathrm{sp} 3}-\mathrm{CF}_{3}$ bonds in excellent yield (49-51, 87-93\% yield).

To further demonstrate the utility of this decarboxylative trifluoromethylation protocol, we performed a series of late-stage modifications on medicinal agents and natural products (Table 3). To our delight, a large variety of biologically relevant systems that incorporate olefins, carbonyls, alcohols, and heterocycles underwent chemoselective installation of a $\mathrm{CF}_{3}$ moiety (52-63, 30-71\% yield). Remarkably, mupirocin was transformed in good yield, a notable finding given that this natural product incorporates an epoxide, a diol, and a Michael acceptor $(63,45 \%$ yield $)$.

\section{Supplementary Material}

Refer to Web version on PubMed Central for supplementary material.

\section{ACKNOWLEDGMENTS}

Financial support was provided by the NIHGMS (RO1 GM103558-05), and kind gifts from Merck, BMS, Pfizer, Janssen, and Eli Lilly are acknowledged. J.A.K. thanks the NSF GRFP (DGE 1656466) for funding.

\section{REFERENCES}

(1). (a)Hagmann WK J. Med. Chem 2008, 51, 4359. [PubMed: 18570365] (b)Purser S; Moore PR; Swallow S; Gouverneur V Chem. Soc. Rev 2008, 37, 320. [PubMed: 18197348] (c)Müller K; Faeh C; Diederich F Science 2007, 317, 1881. [PubMed: 17901324] (d)Bégué JP; Bonnet- 
Delpon D Bioorganic and Medicinal Chemistry of Fluorine; J. Wiley \& Sons: Hoboken, NJ, 2008.

(2). Alonso C; de Marigorta EM; Rubiales G; Palacios F Chem. Rev 2015, 115, 1847. [PubMed: 25635524]

(3). (a)Merino E; Nevado C Chem. Soc. Rev 2014, 43, 6598. [PubMed: 24789472] (b)He Z; Tan P; Hu J Org. Lett 2016, 18, 72. [PubMed: 26651277] (c)Xu X; Chen H; He J; Xu H Chin. J. Chem 2017, 35, 1665.

(4). (a)Chen Q-Y; Wu S-WJ Chem. Soc., Chem. Commun 1989, 705.(b)Chen Q-Y; Duan J-X Tetrahedron Lett. 1993, 34, 4241.(c)Novak P; Lishchynskyi A; Grushin VV J. Am. Chem. Soc 2012, 134, 16167. [PubMed: 22998369] (d)Tyrra W; Naumann D; Quadt S; Buslei S; Yagupolskii YL; Kremlev MM J. Fluorine Chem 2007, 128, 813.(e)Sevenard DDV; Kirsch P; Roschenthaler GV; Movchun VN; Kolomeitsev AA Synlett 2001, 2001, 379.

(5). Xu J; Xiao B; Xie CQ; Luo DF; Liu L; Fu Y Angew. Chem., Int. Ed 2012, 51, 12551.

(6). Twilton J; Le C; Zhang P; Shaw MH; Evans RW; MacMillan DWC Nature Rev 2017, 1, 0052.

(7). Jin Y; Fu H Asian J. Org. Chem 2017, 6, 368.

(8). Bloom S; Liu C; Kolmel DK; Qiao JX; Zhang Y; Poss MA; Ewing WR; MacMillan DWC Nat. Chem 2018, 10, 205. [PubMed: 29359756]

(9). Liu L; Zhu M; Yu H-T; Zhang W-X; Xi ZJ Am. Chem. Soc 2017, 139, 13688.

(10). Freiberg M; Meyerstein DJ Chem. Soc., Faraday Trans. 1 1980, 76, 1825.

(11). Liang Y; Zhang X; MacMillan DWC ChemRxiv 2018, DOI: 10.26434/chemrxiv.5877868.v1.

(12). Choi GJ; Zhu Q; Miller DC; Gu CJ; Knowles RR Nature 2016, 539, 268. [PubMed: 27732585]

(13). Charpentier J; Fruh N; Togni A Chem. Rev 2015, 115, 650. [PubMed: 25152082]

(14). Huang Y; Fang X; Lin X; Li H; He W; Huang K-W; Yuan Y; Weng Z Tetrahedron 2012, 68, 9949.

(15). (a)Umemoto T Chem. Rev 1996, 96, 1757. [PubMed: 11848810] (b)Shibata N; Matsnev A; Cahard D Beilstein J. Org. Chem 2010, 6, 65. [PubMed: 20703379] (c)Charpentier J; Früh N; Togni A Chem. Rev 2015, 115, 650. [PubMed: 25152082] (d)Chachignon H; Cahard D Chin. J. Chem 2016, 34, 445.

(16). Mizuta S; Verhoog S; Wang X; Shibata N; Gouverneur V; Médebielle MJ Fluorine Chem. 2013, $155,124$.

(17). Vantourout JC; Miras HN; Isidro-Llobet A; Sproules S; Watson AJB J. Am. Chem. Soc 2017, 139, 4769. [PubMed: 28266843]

(18). (a)Shen H; Liu Z; Zhang P; Tan X; Zhang Z; Li CJ Am. Chem. Soc 2017, 139, 9843.(b)Tan X; Liu Z; Shen H; Zhang P; Zhang Z; Li CJ Am. Chem. Soc 2017, 139, 12430.

(19). (a)Patani GA; LaVoie EJ Chem. Rev 1996, 96, 3147. [PubMed: 11848856] (b)Meanwell NA J. Med. Chem 2011, 54, 2529. [PubMed: 21413808] 

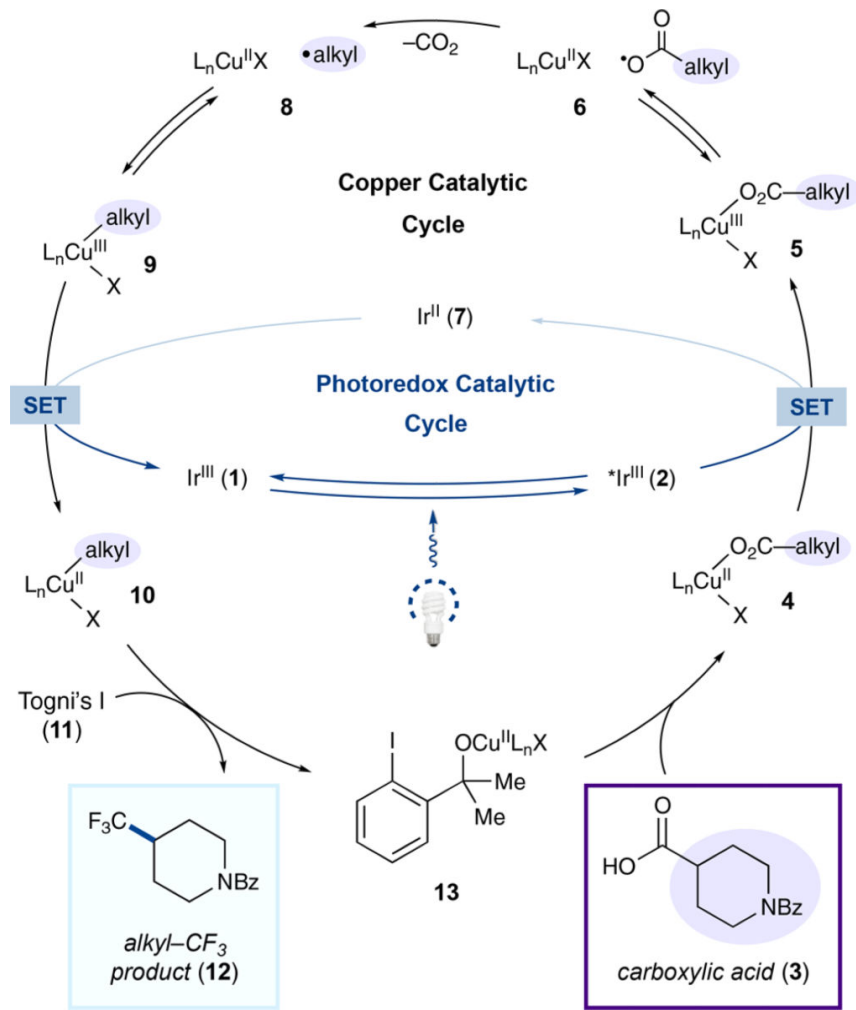

Scheme 1.

Pathway of Decarboxylative Trifluoromethylation product (12) 
Table 1.

Decarboxylative Trifluoromethylation: Initial Studies ${ }^{a}$

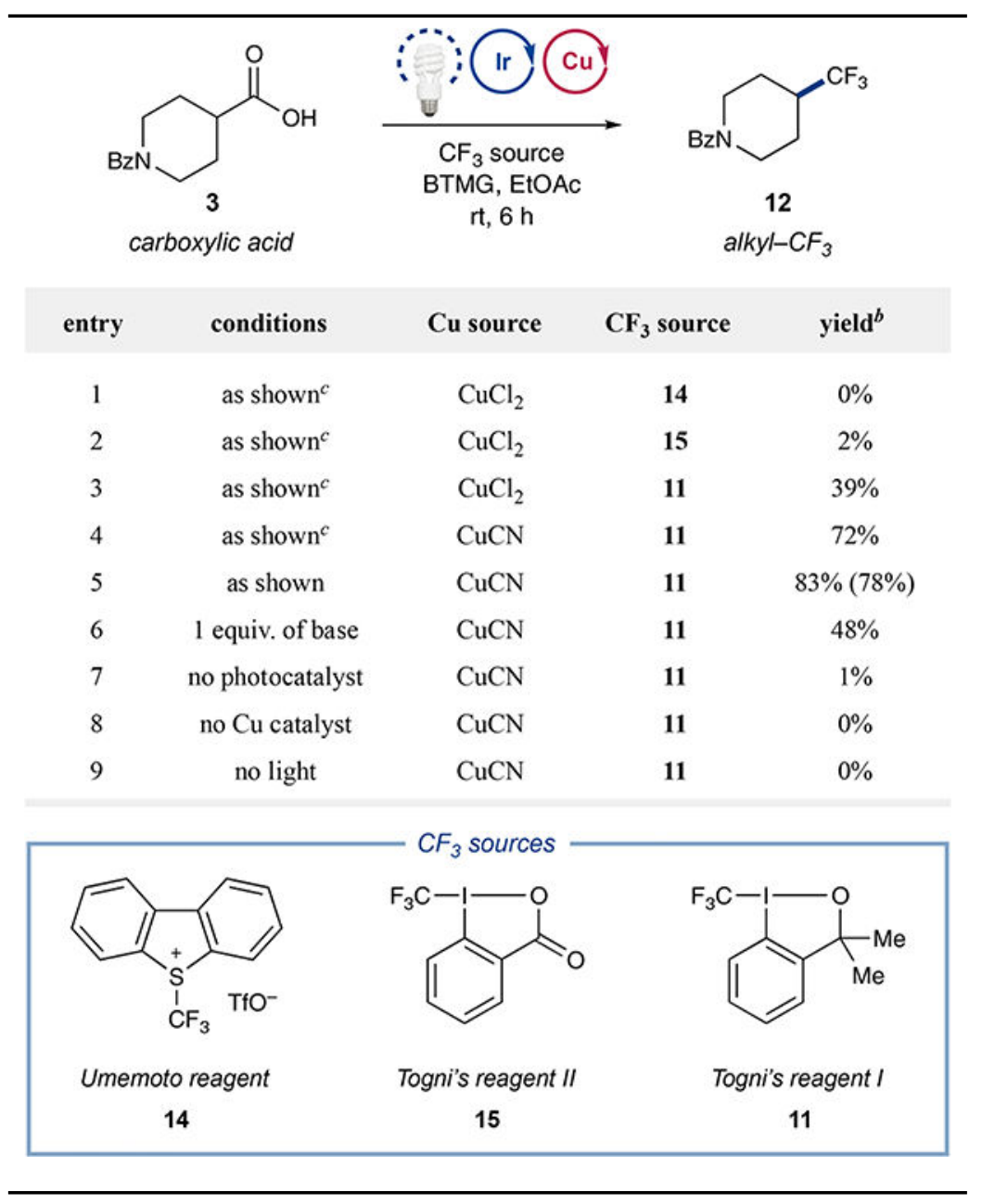

${ }^{a}$ Performed with acid $3(0.05 \mathrm{mmol})$, photocatalyst 1 (1 mol\%), Cu source (20 mol\%), bathophenanthroline (30 mol\%), 2-tert-butyl-1,1,3,3tetramethylguanidine (BTMG, 0.5 equiv), $\mathrm{CF}_{3}$ source (1.25 equiv), and $\mathrm{H}_{2} \mathrm{O}$ (30 equiv) in EtOAc ( $\left.0.025 \mathrm{M}\right)$.

$b_{\text {Yields by }}{ }^{19}$ F NMR analysis. Yields in parentheses are isolated yields.

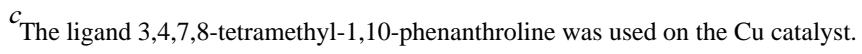



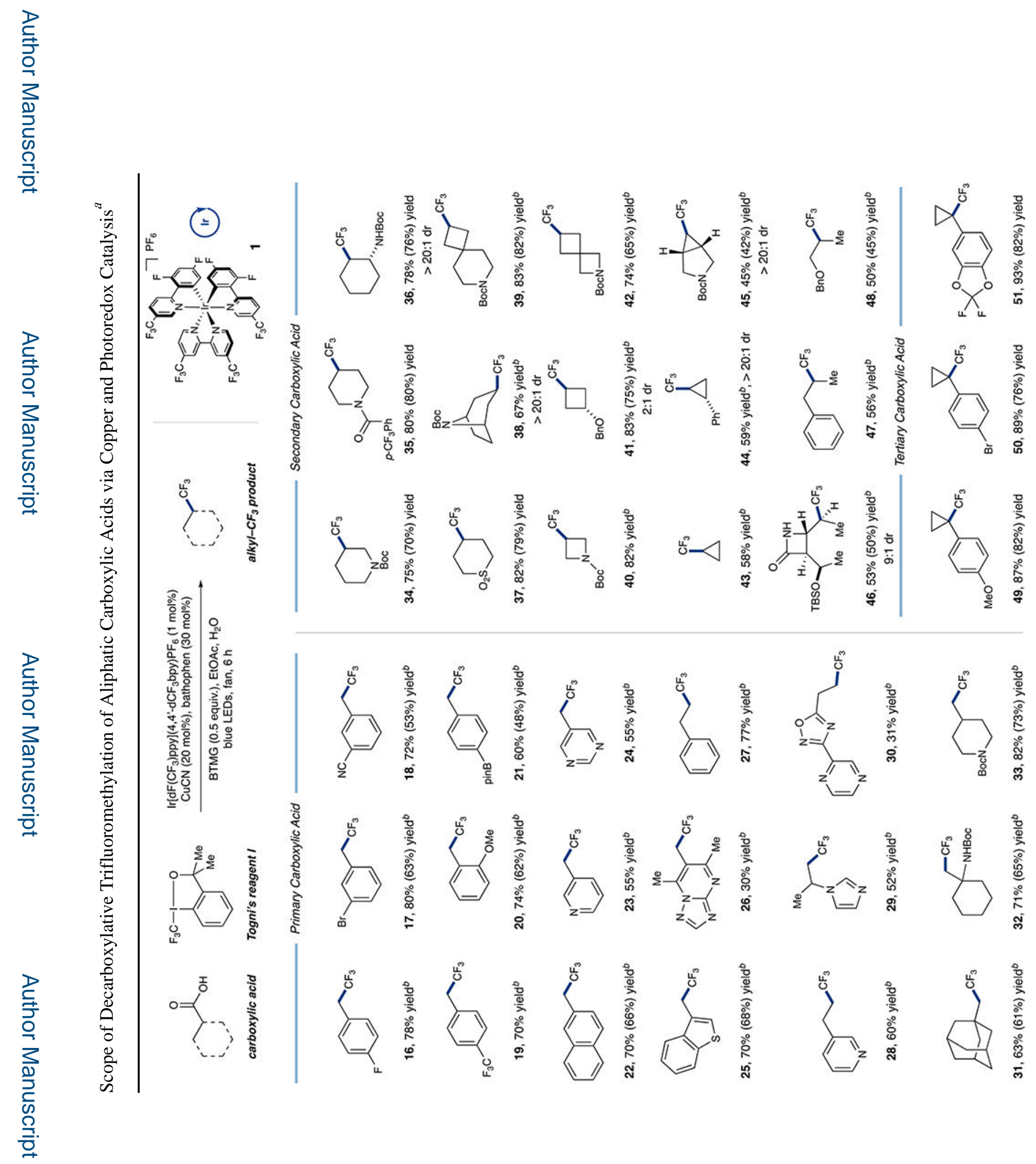

J Am Chem Soc. Author manuscript; available in PMC 2019 May 28. 


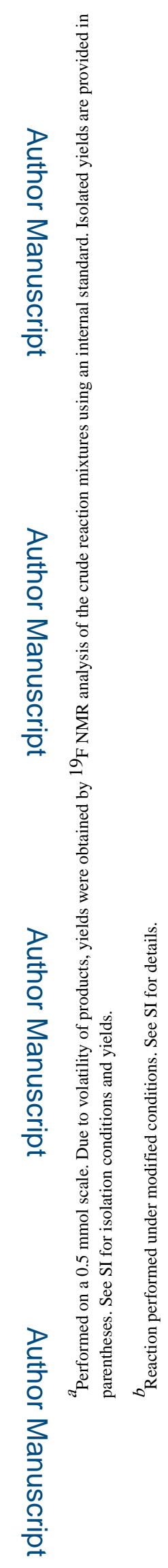

J Am Chem Soc. Author manuscript; available in PMC 2019 May 28. 


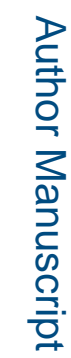

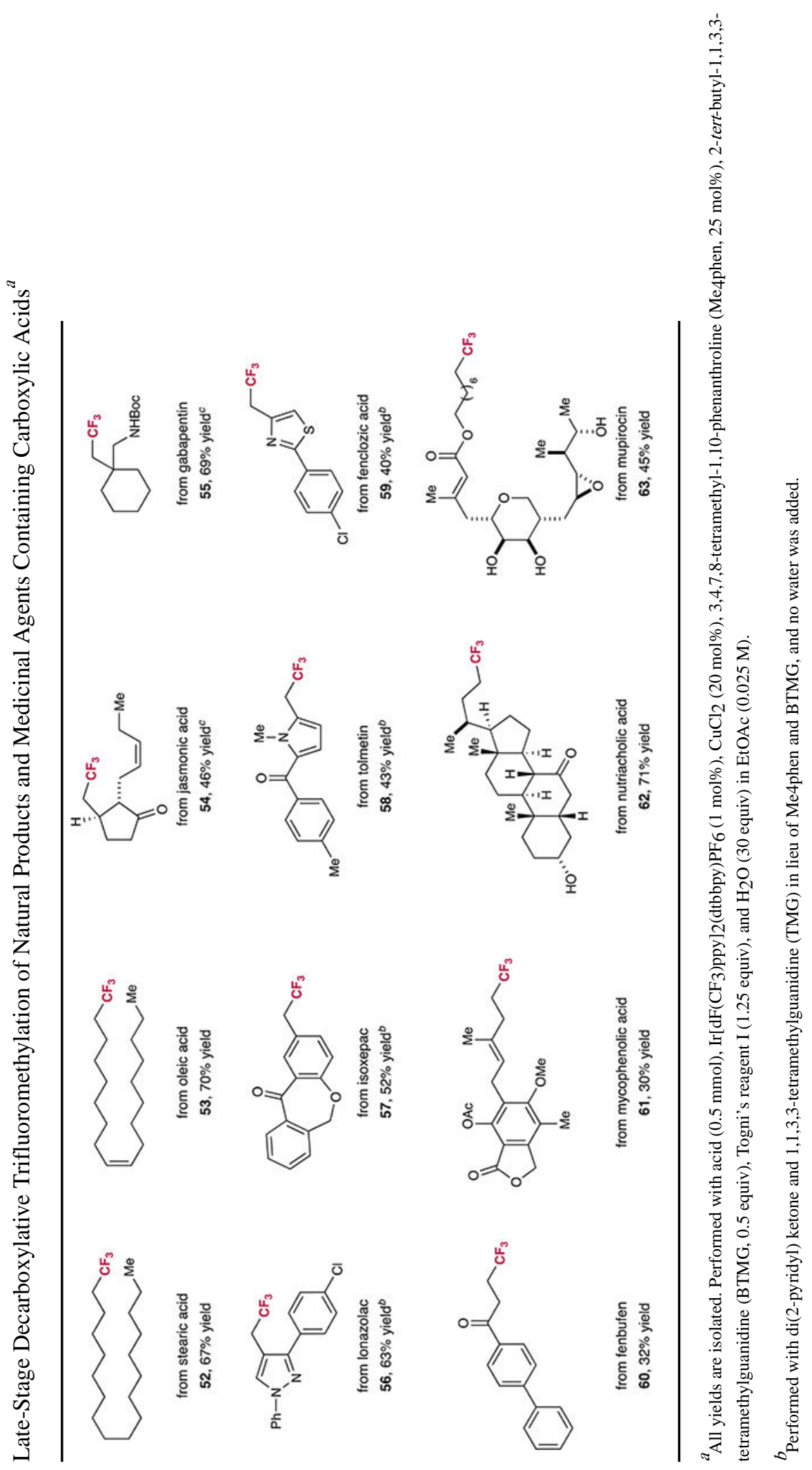

J Am Chem Soc. Author manuscript; available in PMC 2019 May 28. 